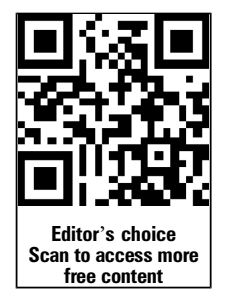

\title{
How to minimise the health risks to athletes who compete in weight-sensitive sports review and position statement on behalf of the Ad Hoc Research Working Group on Body Composition, Health and Performance, under the auspices of the IOC Medical Commission
}

\author{
Jorunn Sundgot-Borgen, ${ }^{1}$ Nanna L Meyer, ${ }^{2}$ Timothy G Lohman, ${ }^{3}$ Timothy R Ackland, ${ }^{4}$ \\ Ronald J Maughan, ${ }^{5}$ Arthur D Stewart, ${ }^{6}$ Wolfram Müller ${ }^{7}$
}

For numbered affiliations see end of article.

\section{Correspondence to} Professor Jorunn SundgotBorgen, The Norwegian School of Sport Sciences, PO Box 4014, Ullevaal stadion, Oslo 0806, Norway; jorunn. sundgot-borgen@nih.no

Accepted 23 August 2013
To cite: Sundgot-Borgen J, Meyer NL, Lohman TG, et al. Br J Sports Med 2013;47:1012-1022.

\begin{abstract}
A focus on low body weight and body fat content, combined with regulations in some weight-sensitive sports, are considered risk factors for extreme dieting, eating disorders (EDs) and related health consequences among athletes. At present there are, from a health perspective, no generally accepted optimum values for body weight or percentage of fat mass in different sports and there is no 'gold standard' method for body composition assessment in athletes. On the basis of health considerations as well as performance, medical support teams should know how to approach elite athletes who seek to achieve an unrealistic body composition and how to prevent restrictive eating practices from developing into an ED. In addition, these teams must know when to raise the alarm and how to advice athletes who are affected by extreme dieting or clinical EDs. However, there is no consensus on when athletes struggling with extreme dieting or EDs should be referred for specialist medical treatment or removed from competition. Based on the present review, we conclude that there is a need for (1) sport-specific and gender-specific preventive programmes, (2) criteria for raising alarm and 'does not start' (DNS) for athletes with EDs and (3) modifications to the regulations in some sports. Further, the key areas for research identified include the development of standard methods for body composition assessment in elite athletes; screening measures for EDs among athletes; development and testing of prevention programmes; investigating the short and long-term effects of extreme dieting; and EDs on health and performance.
\end{abstract}

\section{INTRODUCTION}

In various sports body weight and body composition are crucial performance variables. ${ }^{1}$ Some athletes are genetically suited to the specific anthropometric demands of the sport/weight class in which they compete, but many elite athletes struggle with extreme dieting and eating disorders (EDs) as they attempt to conform to competition regulations that are ill suited to their physique. ${ }^{2}$ As a consequence, athletes with very low body weight and/or body fat, frequent weight fluctuation, EDs and insufficient bone density are often found in weight-sensitive sports, with a high prevalence of menstrual dysfunction in women. ${ }^{3}$ Medical staff, including sports physicians, nutritionists and exercise scientists, experience challenges in handling the issues of optimum body composition, dieting and EDs in elite athletes. ${ }^{4} 5$ Furthermore, most sport nutritionists experience challenges related to application of minimum/maximum body composition or body mass values for health and performance, especially when confronted with a lack of knowledge among coaches and other support team members. ${ }^{5}$ Therefore, the aim of this article is to review the current knowledge related to minimising the risks associated with extreme weight control and EDs in elite athletes.

\section{Definitions}

Weight-sensitive sports can be classified into three main groups: (1) gravitational sports, in which high body weight restricts performance because moving the body against gravity is an essential part of these sports. Among these sports are long-distance running, cross-country skiing, road and mountain bike cycling, ski jumping and jumping in athletics. (2) Weight-class sports, including combat sports such as wrestling, judo, boxing, taekwondo, as well as weight lifting and lightweight rowing. (3) Aesthetically judged sports such as rhythmic and artistic gymnastics, figure skating, diving and synchronised swimming. ${ }^{15}$

Energy availability is defined as the amount of 'unused' dietary energy remaining for all other metabolic processes after the energy cost of exercise training is subtracted from the daily energy intake. $^{6}$

The disordered eating (DE) continuum starts with appropriate eating and exercise behaviours, including healthy dieting (such as lowering energy intake and gradual weight loss) or occasional use of more extreme weight-loss methods such as shortterm restrictive diets $(<30 \mathrm{kcal} / \mathrm{kg}$ fat-free mass (FFM) per day). These behaviours may progress to chronic dieting and frequent weight fluctuation, fasting, passive (eg, sauna or hot baths) or active dehydration (eg, exercise with sweat suits), purging such as use of laxatives, diuretics, vomiting, diet pills with or without excessive training. The continuum ends with clinical EDs, where athletes 
struggle with extreme dieting, distorted body image, weight fluctuation, abnormal eating behaviours and variable performance. ${ }^{7}$ Athletes can be underweight, normal weight or overweight, irrespective of the presence of extreme dieting periods or EDs. ${ }^{8}$ Athletes may relate to, if not fixate on, a theoretical minimum weight which represents an appropriate level of FFM, and zero excess fat, likely to optimise performance, but in practice this may be very difficult to achieve. The most frequent ED diagnosis among elite athletes is that of an ED not otherwise specified (EDNOS). Relatively few meet the criteria for bulimia nervosa (BN) and or anorexia nervosa (AN). ${ }^{9} 10$

The female athlete triad refers to the inter-relationship among energy availability, menstrual function and bone mineral density (BMD). This triad may have ED as an early clinical manifestation and includes energy deficiency, functional hypothalamic amenorrhoea and osteoporosis. ${ }^{11}$ A male athlete triad exists but rarely comes to the attention because the reproductive effects are not perceived by men. ${ }^{12-14}$

\section{Risk factors associated with extreme dieting and EDs}

There are no controlled prospective studies focusing on risk factors for EDs in elite athletes. Therefore, the reason why some athletes cross the line from dieting and use of extreme weight-loss methods to clinical EDs is not yet known. It is generally accepted that the pathogenesis of EDs is multifactorial with cultural, individual, family and genetic/biochemical factors playing roles. The second category involves factors specific to the athletic community, such as perfection and strong achievement orientation, the start of sport-specific training, competition, dieting and weight loss at early age, a desire to be lean to increase performance, pressure from coaches and the regulations in some sports. ${ }^{11}$ In aesthetic sports, comments by coaches on an athlete's body composition are associated with a psychological pressure to diet and there is a common belief that judges are influenced by the body composition of the athlete. ${ }^{15} \mathrm{In}$ addition, in sports with weight categories such as wrestling, judo, karate and lightweight rowing, athletes aim for a competitive advantage by achieving the lowest possible body weight with greatest possible strength and longest possible limb length. Weight loss prior to competition, especially in weight-class sports is viewed as an essential part of the sport, and few attempt to question the methods followed to achieve the required weight loss. Furthermore, data suggest that pressures on athletes to reduce weight and body fat can create a culture for DE. ${ }^{16}$ Thus, in some of the weight-sensitive sports, such as the weight class and judged sports, there might be an indirectly increased risk for ED. ${ }^{17} 18$ Recently, a prospective controlled study showed that athletes who reported dieting and the desire to be leaner to improve performance are more likely to develop EDs. ${ }^{10} 19$ However, it is important to keep in mind that controlled, longitudinal studies are needed to examine the true risks and trigger factors for the development of EDs in sports.

\section{Why should we oppose extreme dieting and EDs?}

The prevalence of dieting and rapid weight loss among athletes in weight-sensitive sports seems to be as common and inappropriate today as it was many years ago. ${ }^{20}$ Up to $94 \%$ of elite athletes competing in weight-sensitive sports report dieting and use of extreme weight control measures to achieve weight target prior to competition. ${ }^{2}$ Although several studies have reported suboptimal energy and nutrient intake in weight-sensitive sports, the prevalence of athletes with low energy availability (LEA) without ED or DE has not been evaluated. ${ }^{6}$ This is because of the lack of standardisation related to assessment of
LEA. A high prevalence of DE and ED has been reported in female athletes in all of the three groups of weight-sensitive sports described above. ${ }^{4} 7$ For male athletes, the prevalence is higher in gravitational sports, such as ski jumping, other jumping events and endurance-type sports, where excess body weight is associated with a competitive disadvantage. ${ }^{4}$ In aesthetic sports, the prevalence is estimated to be about $40 \%$, and in weight-class sports about $30 \%$ for elite female athletes. For elite male athletes, the prevalence in weight-class sports is about $18 \%$ and $24 \%$ in gravitational sports. In contrast, the prevalence in team sports is $5 \%$ in male and about $15 \%$ in elite female athletes. Corresponding values in technical sports are about $4 \%$ and $17 \%$, respectively. ${ }^{7} 21$ The wide range in reported prevalence may be explained by various methodological factors, such as different definitions and assessment tools used, different groups of athletes (eg, age and performance level) and different sport disciplines being studied. It has been claimed that the prevalence seems to be higher in elite athletes than in athletes at lower competitive level and controls ${ }^{7} \quad 22$ and that athletes seemed to be in more severe stages of the disorder, that is, showing a higher frequency of menstrual dysfunction, as compared with non-athletes. ${ }^{3}$ The prevalence of menstrual irregularity varies widely depending on the type of sport and is reported to be as high as $69 \%$ in weight-sensitive sports ${ }^{23}$ in comparison with $3-25 \%$ in control groups. ${ }^{3}$ Also, the prevalence of menstrual dysfunction and low bone mass in female elite athletes competing in weight-sensitive sports is higher than that among female athletes representing sports that are less sensitive to the effects of body weight. ${ }^{3} 24$ Furthermore, DE, menstrual dysfunction and low BMD are associated with musculoskeletal injuries in female athletes. ${ }^{24}$

In recent years, studies have found the presence of the triad in elite athletes representing leanness and non-leanness sports. ${ }^{25}$ There has also been some speculation that a male athlete triad exists, ${ }^{26}$ especially since some studies have observed low bone density values in some male athletes. ${ }^{14} 2728$ Smathers et al $l^{28}$ noted that $9 \%$ of male competitive cyclists and 3\% of agematched and body mass-matched controls were classified as osteoporotic; while as many as $25 \%$ of the cyclists compared to $10 \%$ of the controls were classified as osteopaenic. The pathophysiological explanation is not clear in these studies, and more research is needed to explain this phenomenon of a male athlete triad.

\section{Extreme dieting and ED affect health and performance}

The health effect of extreme dieting and EDs depends on the age, general health and body composition prior to weight loss, the duration, amount and rate of weight loss and the frequency of weight fluctuation. The expected physiological and psychological characteristics and health consequences of various extreme weight control behaviours are expected to affect performance (tables 1 and 2).

No studies have specifically examined the short-term and long-term health effects in groups of elite athletes using extreme dieting and DE during their sports career. It is likely that athletes who suffer from long-term LEA may develop nutrient deficiencies (including anaemia), chronic fatigue and increased risk of infections and illnesses, all of which have the potential to harm health and performance. Physiological and medical complications involve the cardiovascular, gastrointestinal, endocrine, reproductive, skeletal, renal and central nervous systems, as well as psychological stress and depressions. ${ }^{11} 31$ While studies highlight the female athlete triad and the increased risk of injuries among dieting athletes, ${ }^{11}$ long-term data are missing. 
Table 1 The physical/medical symptoms and the psychological/ behavioural characteristics of energy restriction and eating disorders among athletes

\begin{tabular}{|c|c|}
\hline & Characteristics \\
\hline \multicolumn{2}{|l|}{ Physical/medical } \\
\hline $\begin{array}{l}\text { Dermatological/ } \\
\text { dental }\end{array}$ & $\begin{array}{l}\text { Hair loss } \\
\text { Lanugo hair } \\
\text { Dorsal hand callus or abrasions } \\
\text { Dental and gum problems }\end{array}$ \\
\hline Cardiovascular & $\begin{array}{l}\text { Bradycardia } \\
\text { Hypotension }\end{array}$ \\
\hline Endocrine & $\begin{array}{l}\text { Hypoglycaemia } \\
\text { Delayed onset of puberty } \\
\text { Menstrual dysfunction } \\
\text { Stress fracture }\end{array}$ \\
\hline Gastrointestinal & $\begin{array}{l}\text { Swollen parotid glands } \\
\text { Constipation } \\
\text { Postprandial distress }\end{array}$ \\
\hline Renal & $\begin{array}{l}\text { Dehydration } \\
\text { Oedema } \\
\text { Electrolyte disturbances } \\
\text { Muscle cramps } \\
\text { Metabolic alkalosis }\end{array}$ \\
\hline Other & $\begin{array}{l}\text { Significant weight loss/frequent weight fluctuations } \\
\text { Fatigue } \\
\text { Anaemic }\end{array}$ \\
\hline $\begin{array}{l}\text { Psychological/ } \\
\text { behavioural }\end{array}$ & $\begin{array}{l}\text { Restrictive eating, binging and purging } \\
\text { Mood swings } \\
\text { Avoidance of eating/eating situation } \\
\text { Dissatisfaction with body image (especially in the sport } \\
\text { context) } \\
\text { Extreme performance orientation } \\
\text { Low self-esteem } \\
\text { Poor coping skills } \\
\text { Compulsive and excessive training, also when injured } \\
\text { Insomnia } \\
\text { Reduced social activities } \\
\text { Poor concentration }\end{array}$ \\
\hline
\end{tabular}

There are no long-term health data available, except from a recent study reporting that only $72 \%$ of former elite athletes who suffered from EDs during their athletic career reported that they had recovered from ED 15-20 years later. ${ }^{32}$ Health effects of bingeing and purging can be similar to those of severe/chronic energy restriction. However, the gastrointestinal and cardiovascular complications resulting from bingeing and purging behaviours are different from those associated with severe energy restriction (table 2). Moreover, purging by vomiting, diuretics or laxative misuse poses additional problems of dehydration, electrolyte imbalance and is also associated with an increased risk of the use of prescription weight control drugs. ${ }^{33}$ The immune system seems to be particularly susceptible to the effects of energy deficiency. ${ }^{34}$

\section{The child and adolescent athlete: special considerations}

Given the biological changes occurring in male and female athletes during adolescence it is important to remember that the body of a young growing athlete often develops in a direction against the paradigm of the athlete's sport, especially in women and where the sport demands being as lean as possible. This may influence perceptions of self-appearance and performance. Typically, EDs start to develop among adolescents at the age of about 14-17 years when the athletes begin to focus on a particular sport. ${ }^{15}$ In some weight-sensitive sports, such as aesthetic sports, there is a focus on maintaining the lowest possible level of subcutaneous body fat and athletes in aesthetic sports are likely to be weight conscious prior to puberty. ${ }^{17}$ Long-term inadequate energy and nutrient intakes during the growth period can result in delayed pubertal development and retarded growth. ${ }^{35}$ Delayed menarche, bone growth retardation, reduced height, weight and body fat have been reported in gymnasts. ${ }^{36}$ The consequences of long-term LEA (eg, amenorrhoea and imbalance in bone remodelling) are particularly severe for the adolescent athletes since the imbalance of bone remodelling hinders achievement of a high peak bone mass, stature and the

Table 2 Health and performance consequences of various extreme weight control behaviours

\begin{tabular}{|c|c|c|}
\hline $\begin{array}{l}\text { Weight control } \\
\text { behaviour }\end{array}$ & Physiological effects and health consequences & Effect on performance \\
\hline $\begin{array}{l}\text { Fasting or } \\
\text { starvation }\end{array}$ & $\begin{array}{l}\text { Energy and nutrient deficiency, glycogen depletion, loss of lean body mass, } \\
\text { a decrease in metabolic rate and reduced bone mineral density }\end{array}$ & $\begin{array}{l}\text { Poor exercise performance due to general weakness, reduced ability to } \\
\text { cope with pressure, decreased muscle force, and increased } \\
\text { susceptibility for diseases and injuries }\end{array}$ \\
\hline Diet pills & $\begin{array}{l}\text { Typically function by suppressing appetite and may cause a slight increase } \\
\text { in metabolic rate. May induce rapid heart rate, anxiety, nervousness, } \\
\text { inability to sleep and dehydration. Any weight lost is quickly regained once } \\
\text { use is discontinued }\end{array}$ & Indirectly results in poor performance and may be classified as doping \\
\hline $\begin{array}{l}\text { Laxatives or } \\
\text { enemas }\end{array}$ & $\begin{array}{l}\text { Weight loss is primarily water and any weight lost is regained once use is } \\
\text { discontinued. Dehydration and electrolyte imbalances, constipation, cathartic } \\
\text { colon and steatorrhoea (excessive fat in the faeces) are common }\end{array}$ & $\begin{array}{l}\text { May affect concentration and hydration status. May be addictive and } \\
\text { athlete can develop resistance, thus requiring larger and larger doses } \\
\text { to produce the same effect }\end{array}$ \\
\hline Diuretics & $\begin{array}{l}\text { Weight loss is primarily water and any weight lost is quickly regained once } \\
\text { use is discontinued. Dehydration and electrolyte imbalances are not } \\
\text { uncommon }\end{array}$ & Poor performance and classified as doping \\
\hline $\begin{array}{l}\text { Self-induced } \\
\text { vomiting }\end{array}$ & $\begin{array}{l}\text { Large body water losses can lead to dehydration and electrolyte imbalances. } \\
\text { Gastrointestinal problems, including oesophagitis, oesophageal perforation } \\
\text { and oesophageal ulcers may occur }\end{array}$ & $\begin{array}{l}\text { May lead to electrolyte imbalance. Largely ineffective in promoting } \\
\text { weight (body fat) loss }\end{array}$ \\
\hline Saunas & Dehydration and electrolyte imbalances can occur in extreme cases & $\begin{array}{l}\text { Weight loss is primarily water and any weight lost is quickly regained } \\
\text { once fluids are replaced }\end{array}$ \\
\hline Excessive exercise & $\begin{array}{l}\text { If combined with low energy availability it will increase risk of staleness, } \\
\text { chronic fatigue, illness, overuse, injury and menstrual dysfunction }\end{array}$ & Experience the effect of lack of recovery \\
\hline
\end{tabular}


development of the reproductive system. It may take several years to recover, but studies demonstrate a catch-up effect for growth of bone and body mass when energy intake is normalised in young athletes suffering from LEA. ${ }^{37} 38$

\section{The effect on performance}

The effect of extreme dieting and EDs on performance is likely to differ between rapid weight reduction per se, chronic LEA, frequent use of pathological methods and severe psychopathology in EDs. Also, as with health, the effect of weight loss on performance depends on the athlete's initial body fat, the amount of weight loss and the strategy used. Some athletes experience an initial, albeit transient, improvement in performance after short-term reduction in energy availability and weight loss. ${ }^{34}$ The decrease in body weight may induce a direct increase in performance through weight reduction per se or indirectly by increasing maximum oxygen uptake per $\mathrm{kg}$ body weight. The latter factor is crucial for performance in endurance events such as long-distance running and cross-country skiing. Moreover, with weight loss, athletes may feel lighter, and experience a psychological boost, particularly if they believe that lighter means improved performance. However, Ingjer and Sundgot-Borgen ${ }^{39}$ reported the negative consequences of energy deficiency on cardiovascular function and performance: maximum oxygen uptake and running speed of female elite endurance athletes decreased for several months after 2 months with LEA. It is also not clear whether the athletes still had remaining slight energy deficiency after the initial rapid weight reduction or if energy intake was adequate for their training demands. If purging methods place the athlete in a state of inadequate energy availability and psychological stress, then the potential effects on performance are similar to those seen with chronic or severe energy restriction. In addition to causing energy and nutrient deficiencies, purging poses unique problems regarding athletic performance, including most notably dehydration and severe electrolyte abnormalities. Athletes who try to regain body weight after a period of rapid weight loss often report impaired performance and symptoms, such as dizziness, hot flushes, nausea, headache and nosebleeds. ${ }^{2}$ Also, from a psychological point of view, performance is apt to be negatively affected by common consequences of EDs, such as depression, anxiety and decreased concentration.

\section{WHAT CAN WE SUGGEST?}

The American Academy of Pediatrics, the IOC Medical Commission and the American College of Sports Medicine (ACSM) have recommended that national and international sports federations put policies and procedures in place to eliminate potentially harmful weight-loss practices. ${ }^{114041}$ More specifically, they recommend that professionals participating in health maintenance and performance enhancement of athletes should be provided with specific knowledge and problem-solving skills to better prevent, detect and manage extreme dieting, EDs and the triad components. ${ }^{11}{ }^{41}$ Procedures and policies are not specified because best practices may be sport specific. We agree, but based on the mandate of our group we have used existing literature and best practice to suggest guidelines for minimising risk in weight-sensitive sports. We agree with the recommendations listed and discussed in the above-position articles, but add more specific suggestions related to weight control, regulations and when to raise the alarm. To decrease the high number of athletes in weight-sensitive sports who use extreme weight-loss methods and suffer from EDs, the group suggests that the most important measures are: (1) to establish educational initiatives for discouraging extreme dieting and EDs, (2) taking athletes who seek to lose weight/change body composition seriously, (3) modifying rules in some of the sports and (4) developing concrete 'does not start' (DNS) criteria.

\section{Primary prevention}

In terms of prevention, the focus of attention should be on those risk factors most amenable to alteration, in particular, the pressure on athletes to manipulate eating behaviours and body weight in the belief that this will enhance performance and for them to appear thin. Prevention of extreme dieting and EDs, and the treatment of EDs can be organised into three categories. Primary prevention involves education and instruction designed to prevent the onset of extreme dieting and the development of EDs. Secondary prevention focuses on early identification of athletes who are at risk for DE/EDs and follow-up treatment, while tertiary prevention includes treatment of athletes with EDs. Since minimising risk is the aim of this article, treatment is not discussed here, but has been well described elsewhere. ${ }^{29}$

The goal of primary prevention should be to protect athletes from factors that can predispose them to the use of extreme dieting and or development of EDs. Since a high prevalence of adolescent elite athletes are using extreme dieting and meet the criteria for clinical ED, ${ }^{3} 10$ primary prevention should be initiated as early as 9-11 years of age.

\section{Educating those involved with weight-sensitive sports}

Healthcare professionals working with athletes who may be at risk of EDs should possess knowledge and understanding of the following matters.

- Have a firm understanding of the principles of normal growth and maturation, including sexual, skeletal, somatic and behavioural development occurring at this critical stage in the life cycle. This understanding should include the potential changes in self-perceptions and concerns for appearance, especially in aesthetic sports in which physical appearance may be part of the judging process, as well as how training and performance might be affected.

- Be aware of the challenges of the complex association between dieting, energy availability and nutrition, body composition and performance.

- Have good knowledge of the physical, psychological and behavioural symptoms/characteristics and consequences of extreme dieting and EDs (as are summarised in tables 1 and 2).

- Be qualified and experienced in the detection, diagnosis and treatment of DE and EDs.

While it is usually assumed that sport scientists, nutritionists and other healthcare providers have the knowledge and skill as well as established systematic pathways regarding the identification and approach of an athlete at risk for DE and EDs, this is not always the case. ${ }^{5}$ Even physicians and physical therapists lack this knowledge: studies show that only $48 \%$ of physicians and $43 \%$ of physiotherapists, respectively, report that they know how to identify athletes with one or more of the triad components. ${ }^{42}$ Therefore, educating healthcare providers about these issues is needed.

It may be tempting to equate performance with health. Coaches might not recognise that an athlete who is performing well is also exhibiting signs of EDs. Thus, coaches also require knowledge and practical skill related to at-risk athletes.

Athletic trainers and coaches require knowledge about

- how to optimise nutrition, body composition and performance; 
- the principles of physical growth, biological maturation and behavioural development occurring at this critical stage in the life cycle;

- risk factors and consequences related to extreme dieting and EDs (eg, menstrual dysfunction for women, hormonal changes in men, growth and development);

- loss of tissue can cause disastrous performance setbacks;

- how psychological factors relate to health and athletic performance;

- dieting and weight issues should not be a theme from the coach, but should be presented according to the athlete's wish. In such cases, the coach should take the athlete's initiative seriously and refer to professional help. In this respect, the possibility of increasing weight and a change in the competition weight class should also be discussed with the athlete. For young growing athletes and lean adult athletes the focus should be on performance enhancement via nondieting strategies, including improved nutrition, improved health, mental and psychological approaches and physical aspects;

- how to approach athletes with body composition and/or ED problems.

Athletes need knowledge about

- how to optimise energy and nutrient intake and combine this with optimal training;

- how eating behaviour relates to training, performance and body composition;

- health and performance consequences of extreme dieting, DE behaviour, menstrual dysfunction and low BMD;

- the notion that seeking help for a DE/ED behaviour is acceptable and that early intervention may help to prevent escalation of EDs and/or the female triad conditions;

- that weight loss does not necessarily lead to improved performance.

In summary, education is needed at all levels and we suggest that each federation of the different weight-sensitive sports should have sport-specific position statements with guidelines related to optimising nutrition and body composition. To reduce the risk of extreme dieting and EDs mandatory educational programmes for healthcare providers, athletes, coaches/ athletic trainers and other athletics staff members should be implemented on an annual basis.

\section{Guidelines for athletes in weight-sensitive sports who want/ need to reduce weight or change body composition}

Most athletes competing at a high level in weight-sensitive sports are fit and lean, but want to reduce weight to compete in a lower weight class or in the belief that a performance benefit will follow and consider this as 'part of the game'. If the athlete is already lean and/or is under 18 years of age, the coach and healthcare team should motivate the athlete to improve strength and power and compete in a higher weight class. Athletes engaged in aesthetic sports know that extra fat will influence the judges' score and a significant number of these athletes are chronic 'dieters' although they are still growing. ${ }^{17}$ Thus, athletes in weight-sensitive sports who seek to lose weight, change weight class or reduce fat mass, should be guided by healthcare professionals. Recent data by Sundgot-Borgen and Garthe ${ }^{2}$ indicate that a controlled weight-loss intervention in elite athletes does not increase the risk for DE or EDs when guided by a professional sport nutritionist. As for recommendations for weight loss/change in body composition, the authors agree with the recommendations suggested in the recent IOC position stand on nutrition. ${ }^{2}$ However, for the purpose of this article, the recommendations are slightly modified, as listed below:

- A thorough body composition assessment is necessary prior to intervention. Objective measurements of body mass and fat mass should be made by qualified individuals using recommended techniques as outlined in Ackland et al. ${ }^{1}$

- While prioritisation of weight-loss interventions during the off-season is recommended, this is not always practical or realistic. It is the responsibility of the healthcare provider to discuss the timing of weight loss with the coach if it is thought inappropriate. Furthermore, a carefully timed, and to some extent more conservative approach to weight loss may be necessary should it coincide with a period of intense training.

- While there are several effective approaches to support an athlete's weight loss, a 'one size fits all' approach is not supported. Choosing the most appropriate dietary assessment and intervention for an individual athlete is the responsibility of the sport nutritionist/dietitian who should take care not to harm the athlete or burden them with unnecessary recording of food intake.

- Any history or current status of menstrual function for female athletes, or other indicators of low BMD, such as stress fractures, warrant an objective measure of BMD using dual energy e-ray absorptiometry (DXA).

- A nutritional assessment should include blood and urinary markers of nutrient deficiencies. If blood tests indicate specific micronutrient issues (eg, iron, vitamin $\mathrm{B}_{12}$ or vitamin $\mathrm{D}$ deficiencies) it is the responsibility of the sport nutritionist/ dietitian to assist the athlete with appropriate dietary adjustments, safe and effective supplementation, and monitoring. A multivitamin/mineral supplement and $\omega-3$ fatty acids may be provided during weight-loss interventions to assure sufficient micronutrient and essential fat intake.

- Female athletes should consume sufficient energy to avoid menstrual irregularities ( $>30-45 \mathrm{kcal} / \mathrm{kg} /$ day) and a gradual weight loss at approximately $0.5 \mathrm{~kg} /$ week is generally recommended. ${ }^{6}$ To induce a weight loss of $0.5 \mathrm{~kg} /$ week an energy deficit of about $500 \mathrm{kcal} /$ day is needed, but there will be individual differences in how this is achieved. Depending on the training phase, this energy deficit is most likely induced by a combination of decreased energy intake and increased energy expenditure. However, if weight-loss attempts are made during intense training, then adding extra training for weight loss is not recommended. Smaller, perhaps intermittent, deficits are still possible but monitoring of performance, immune and psychological parameters is essential.

- Adjustment of nutritional intake should be made in cooperation with a sport nutritionist/dietitian. Throughout this process, the role of overall good nutrition practices in optimising performance should be emphasised. Daily meal plans should contain $1.5-2 \mathrm{~g} / \mathrm{kg}$ of protein, at least $3-5 \mathrm{~g} / \mathrm{kg}$ of carbohydrate and $\geq 15-20 \%$ of total energy intake from fat, although this regime depends on the sport (eg, endurance athletes need more carbohydrate). The focus should be on foods with a low energy density but high nutrient density to provide satiety. While variety ensures nutrient adequacy, some athletes prefer consistently similar meals, especially for breakfast and lunch. Thus, depending on the athlete, consistency and a frequent meal pattern are key, ensuring that the athlete is not fatigued during training. Recovery meals containing carbohydrates (approximately $1 \mathrm{~g} / \mathrm{kg}$ ) and protein (about $20-25 \mathrm{~g}$ or $0.25 \mathrm{~g} / \mathrm{kg}$ ) should be encouraged within $30 \mathrm{~min}$ after training sessions to optimise recovery, and these 
should include a variety of foods. To avoid extra energy by adding a recovery meal, it is recommended that the recovery meal is one of the planned meals for the day.

- To maintain muscle mass during phases of energy deficits, extra protein, ${ }^{43}$ possibly in combination with strength training, is recommended. ${ }^{44}$

- It has been suggested that the proportion of body fat should be no lower than 5\% for men and 12\% for women after weight loss. $^{2} 45$ However, some athletes are better able than others to tolerate a low body fat without hormonal disturbances and/or other health and performance related impairments. A basic problem is the limited measurement accuracy obtainable using today's techniques. ${ }^{1}$

- Changes in body composition should be monitored on a regular basis including a period of at least 2 months after the weight or body fat goal has been reached to detect any continued or unwarranted losses or weight fluctuations. If a history of $\mathrm{DE} / \mathrm{ED}$ is present, a more intense and longer follow-up is suggested. Weight-class athletes are encouraged not to be more than $\sim 3 \%$ over their competition weight and to lose no more than $2 \%$ in rapid precompetition weight loss (depending on time from weigh-in to competition and on recovery strategies).

- For some athletes, health and performance can benefit from a gain in lean body mass, even if it means they move up a weight class. The weight gain period should be controlled and stabilised after the athlete has reached his/her goal. If an increased lean mass is the goal, a modest positive energy balance combined with strength training may be the optimum strategy.

To minimise the threat to health and performance, many sports have adopted codes of practice for making weight. This is strongly encouraged as one of the most important prevention strategies for minimising the prevalence of and risks associated with ED.

\section{Body composition assessment}

Although it may seem simple to specify a minimum acceptable body fat content, the absence of a reliable method for body composition assessment precludes this option. Different measurements are available, but all come with their own assumptions and problems, and there is no universally accepted gold standard. ${ }^{1}$ Furthermore, responsibility for body composition measurements falls within different professional realms-which include the sports scientist, dietitian and clinician-in different situations. For example, asynchronous diurnal variation in stature and mass affects all measures, sufficient to alter body mass index (BMI) by 1 unit in a typical adult in a $24 \mathrm{~h}$ period, even in the absence of exercise-induced dehydration. Hydration status affects most measurements, so standardisation of hydration status is essential. DXA scans offer repeatable estimates of fat, lean and bone mineral masses, but results are specific to the manufacturer and software revisions and are not necessarily interchangeable. Software algorithms predicting fat and fat-free soft tissues may become unstable in highly muscular and very lean individuals. With appropriate operator training, fat patterning by anthropometry and ultrasound offers a promising approach and merits further investigation. ${ }^{1} 46 \quad 47$ For all approaches there is a need for quality-assured measures that take account of intratester and intertester error. Therefore, we recommend that skinfolds or DXA be used to monitor changes in body composition with interventions that seek to induce weight loss or change body composition. ${ }^{5}$ Although suggestions as to the optimal body fat content for various sports may be found in some textbooks, none of these are evidence based. Likewise, critical values for body fat and existing guidelines are also not evidence based, although $12 \%$ and $5 \%$ have been suggested as critical values for female and male athletes, respectively. $^{2} 48$ Given the variability between individuals and the errors inherent in assessment of body fat content, it seems unlikely that a single critical value can ever be identified. Nonetheless, the values stated above may serve as a useful guide.

\section{Regulations}

The magnitude of impairment caused by acute weight-loss strategies seems to depend on the time from weigh-in to competition and recovery strategy used. ${ }^{49}$ Most athletes in Olympic weightclass sports have $2-3 \mathrm{~h}$ to recover from weigh-in. ${ }^{2}$ The weightclass system (few weight classes/categories that are separated by many kilograms) and the timing of weigh-in (a long time period from weigh-in to competition starts compared with only one weigh-in during tournaments) and procedure during competitive events may encourage athletes to use extreme weight-loss methods. ${ }^{2}$ To prevent athletes from striving towards unrealistic weight goals to perform well, the authors suggest modification of some regulations within different weight-sensitive sports. These modifications are related to weigh-in times, number of weight classes, use of BMI or other metric as a cut-off value for participation, and subjective judging. The suggested modifications should be discussed with the individual international federations. As can be seen in table 3, the number of weight classes differs from one competition to the other and the weigh-in time for some of the sports encourages the athletes to lose extreme amounts of weight.

Based on a review of the literature concerning rapid weight loss and EDs and on practical experience, the following modifications have been suggested by the group.

- A weigh-in time of not more than 2-3 h before competition should be implemented. In sports such as wrestling and taekwondo it will be more difficult for the competitors to rapidly lose a great amount of weight.

- Sports federations should have the same weight categories at national and international competition.

- More weight categories should be implemented, especially in the low-weight and middle-weight classes and, particularly, in the female weight classes.

- There should be a sufficient number of weight categories and all international and national competitions should use the same categories. Changing to a lower weight class during season should not be accepted. This could lead to less weight fluctuations and fewer occasions of weight fluctuation.

- Accepting some discretion in the weight allowance (eg, 1$2 \mathrm{~kg}$ overweight limit) during the season in smaller tournaments might reduce the frequency of weight loss.

- There is a need for a 'competition certificate' where athletes must have a minimum body mass and percentage of fat or sum of skinfolds measured at an agreed and appropriate hydration level. However, in this regard there is a need for research on how to apply the most valid and reliable methods for measuring percentage of fat and hydration status. ${ }^{5}$

In other sports, for example in ski jumping, the BMI is currently used in the regulations to counteract the low weight tendency. This was an important first step in ski jumping, ${ }^{50-52}$ based on cooperative work of the International Federation of Skiing (FIS) with the IOC. However, further research and common discussions among experts from the fields of sports 
Table 3 Rules for competition and weigh-in procedures in different weight-class sports

\begin{tabular}{|c|c|c|c|}
\hline Sport & Competition & Number of weight categories & Weight-in procedures \\
\hline $\begin{array}{l}\text { Wrestling } \\
\text { Senior International } \\
\text { (Greco-Roman and } \\
\text { freestyle) }\end{array}$ & $\begin{array}{l}1 \text { bout }=3 \times 2 \text { min rounds. Each weight } \\
\text { category is contested over } 1 \text { day. } \leq 4 \text { bouts } \\
\text { each day of competition (competition session } \\
\text { lasts } \leq 4 \mathrm{~h} \text { ) }\end{array}$ & $\begin{array}{l}\text { Male : female } \\
7: 7 \\
4^{*}\end{array}$ & $\begin{array}{l}\text { One weigh-in ( } 30 \mathrm{~min} \text { period) in the evening } \\
\text { before the tournament/competition starts }\end{array}$ \\
\hline $\begin{array}{l}\text { Boxing } \\
\text { Amateur }\end{array}$ & $\begin{array}{l}1 \text { bout }=3 \times 3 \text { min rounds. Competition every } \\
\text { second day with } 4-5 \text { bouts during the } \\
\text { tournament }\end{array}$ & $\begin{array}{l}\text { Male : female } \\
11: 13 \\
3^{*}\end{array}$ & $\begin{array}{l}\text { All boxers have weight-in in the morning of the } \\
\text { first competition day. During tournaments only } \\
\text { those drawn to box have to weigh-in on the } \\
\text { morning. There are at least } 3 \mathrm{~h} \text { between } \\
\text { weight-in and start of the competition }\end{array}$ \\
\hline Judo & $\begin{array}{l}1 \text { bout=5 min } \\
\text { Each weight category is contested over } \\
1 \text { day. } \\
4-5 \text { bouts with minimum } 10 \text { min between } \\
\text { bouts }\end{array}$ & $\begin{array}{l}\text { Male : female } \\
8: 7\end{array}$ & $\begin{array}{l}\text { Weigh-in in the morning of the competition ( } 1 \mathrm{~h} \\
\text { period). } \\
\text { There are at least } 2 \mathrm{~h} \text { between weight-in and } \\
\text { start of the competition }\end{array}$ \\
\hline Taekwondo & $\begin{array}{l}1 \text { bout }=3 \times 3 \text { min rounds. Each weight } \\
\text { category is contested over } 1 \text { day. } 5-8 \text { bouts } \\
\text { during competition }\end{array}$ & $\begin{array}{l}\text { Male : female } \\
7: 7 \\
4^{*} 4^{*}\end{array}$ & $\begin{array}{l}\text { Weigh-in in the evening before competition. One } \\
\text { weigh-in at the start of competition }\end{array}$ \\
\hline Lightweight rowing & $\begin{array}{l}\text { Race is over a } 2000 \mathrm{~m} \text { course. Compete } \\
\text { every second day over a period of } 7 \text { days }\end{array}$ & $\begin{array}{l}\text { Male (female) } \\
\text { Average weight of crew shall not exceed } 70 \\
\text { (57) } \mathrm{kg} \text {. An individual weight }>72.5(59) \mathrm{kg} \\
\text { is not accepted. Maximum weight for a } \\
\text { single sculler is }>72.5(59) \mathrm{kg}\end{array}$ & $\begin{array}{l}\text { Weigh-in each day and for each event. Weight-in } \\
\text { not less than } 1 \mathrm{~h} \text { and not more than } 2 \mathrm{~h} \text { before } \\
\text { start of race }\end{array}$ \\
\hline
\end{tabular}

*Olympics

medicine, biomechanics/aerodynamics and from sports practice are necessary to develop the grounds on which regulations can be based to ensure effective protection of athletes' health and that are designed to last for longer periods, consider fairness and practicability, and that are transparent for the audience. The cooperation between the FIS and the IOC concerning ski jumping can be seen as a role model for other sports in which changes to the regulations can be used as an effective tool for supporting the primary goal of the IOC medical code (ie, the protection of the athlete's health), which is also the primary aim of all International Federation Medical Commissions.

In aesthetic sports, such as rhythmic gymnastics, synchronised swimming, figure skating and diving, there are no published articles on the 'risks' of judging in aesthetic sports. We know that judges comment on body type and are influenced by the perceived aesthetics of the performer. Athletes also report starting to diet due to judges' comments after competitive events. A more objective judging system has been implemented in figure skating and this has been widely accepted. It is expected that this will de-emphasise the focus on leanness at least to some extent.

\section{Secondary prevention}

The main goals in secondary prevention should be to identify athletes better with extreme dieting and EDs, to introduce education and treatment, to limit the progression (of extreme dieting) and to reduce the severity and duration of EDs. It has been suggested that earlier treatment results in fewer health risks for the athlete and also an earlier return to training and competition. $^{11}$

Measurement methods to identify DE include self-report, observation, symptom checklists and clinical interviews. ${ }^{4}$ Different screening instruments have been developed over time to make it easier to identify people at risk of developing EDs and to assist in diagnosis of these disorders.

Practitioners should proceed with caution when considering the use of self-report psychometric questionnaires such as the Eating Disorder Inventory, Eating Attitude Test and the Eating Disorder
Examination Questionnaire to screen for behavioural and cognitive characteristics of DE in athletes. ${ }^{53-55}$ Although the questionnaires have been widely used to screen athletes for DE, they have not been tested for external validity with athletic populations and, consequently, may result in inaccurate information. ${ }^{7}$ Therefore, there is a need for development and validation of the existing questionnaires and probably development of new sport-specific screening tools. Such tests must be reliable, sensitive, specific and acceptable to the screening population and subject to quality assurance. At present, a combination of standardised surveys and clinical interview is regarded as the optimum method to identify EDs among elite athletes, ${ }^{35}$ while true AN, BN and EDNOS in athletes can be diagnosed only through clinical interview.

Failure to meet all criteria for AN or BN should not deter the healthcare provider from offering early and comprehensive intervention, because early recognition and intervention with EDNOS can prevent athletes from developing $\mathrm{AN}$ or $\mathrm{BN}{ }^{11}$ Even in the absence of a clinical ED, restrictive and purging behaviours are of concern because they reduce energy availability. Histories of these behaviours are of interest because their effects on bone are cumulative. However, it is important not to overdiagnose in the highly motivated athlete whose controlled eating behaviour is part of a carefully regulated lifestyle for optimal performance.

\section{Recognition of DE/EDs}

It is important for healthcare teams and coaches to know that athletes usually mention problems related to extreme dieting or EDs only when asked directly or when they are extremely tired, when performance is levelling off, and when they are highly concerned for their health. Generally, the athlete may describe symptoms that do not necessarily point to an ED, such as headaches, constipation, diarrhoea, sleeping problems, breathing problems, dizziness, sadness or tiredness. Regardless of which complaints/symptoms are presented during the first consultation, the health professional should search for possible underlying causes. Questions about food intake, dieting methods and training should be straightforward and concrete (table 4). Since 
Table 4 Screening the athlete: ABCDE Assessment

\begin{tabular}{|c|c|c|}
\hline $\begin{array}{l}\text { ABCDE } \\
\text { Assessment }\end{array}$ & Measures & Comments \\
\hline Anthropometric & $\begin{array}{l}\text { Stature } \\
\text { Sitting height } \\
\text { Body mass } \\
\text { - Body composition } \\
\text { Girth and breadths } \\
\text { BMI } \\
\text { Ml }\end{array}$ & $\begin{array}{l}\text { Valid and reliable methods of body composition should be sought (eg, DXA, skinfold assessment using } \\
\text { the ISAK standards; 4-component models assessing fat, fat-free and lean tissue mass and total body } \\
\text { water; measurement of hydration status using urine specific gravity recommended for all anthropometric } \\
\text { assessments) } \\
\text { Careful reflection is required to ascertain whether assessment of body mass and composition may trigger } \\
\text { more problems } \\
\text { BMI and MI are measures (indices) for 'relative body weight' (ponderosity), but not for body composition }\end{array}$ \\
\hline Biochemical & $\begin{array}{l}\text { Complete blood count } \\
\text { Complete metabolic panel } \\
\text { - Lipid panel } \\
\text { - Iron profile } \\
\text { Thyroid function (eg, TSH and T3) } \\
\text { Oestradiol, testosterone, progesterone, } \\
\text { prolactin, LH and FSH } \\
\text { Cortisol } \\
\text { - } 25(\mathrm{OH}) \text { Vitamin D } \\
\text { - Urine analysis } \\
\text { - Pregnancy test }\end{array}$ & $\begin{array}{l}\text { In females with menstrual dysfunction, prolactin needs to be assessed to rule out pituitary tumour; if } \\
\text { ovarian cysts and oligomenorrhoea, androgens should be assessed } \\
\text { Oestradiol and testosterone should be included in men and women athletes }\end{array}$ \\
\hline Clinical & $\begin{array}{l}\text { - History } \\
\text { - Physical examination } \\
\text { - Medications } \\
\text { - Dietary supplements }\end{array}$ & $\begin{array}{l}\text { Medical history should include DE and EDs. If this is a preparticipation physical examination, then include } \\
\text { a general medical history, including menstrual history/status, bone health, history of stress fracture and } \\
\text { other injuries, osteoporosis. Screening for DE and EDs with screening tools and/or clinical interview and } \\
\text { identification of physical signs and symptoms (see tables } 1 \text { and 2) }\end{array}$ \\
\hline Dietary & $\begin{array}{l}\text { Quantity } \\
\text { Quality } \\
\text { - Timing }\end{array}$ & $\begin{array}{l}\text { Energy intake, energy density; macronutrients (expressed in g/kg/d) and micronutrients, fluid balance and } \\
\text { hydration (including sweat rate), food restrictions, allergies, intolerance; scary foods; nutrient and fluid } \\
\text { timing; carbohydrate availability during intense training; carbohydrate and fibre related to appetite; } \\
\text { recovery nutrition; competition preparation and fuelling, travel nutrition and appetite issues during travel } \\
\text { or intense training } \\
\text { Dietary assessment methods: consider validity and reliability, }{ }_{1}^{58} \text { as well as additional burden and stress on } \\
\text { athletes with DE/ED when using diaries and food logs } \\
\text { Energy availability, including the assessment of energy expenditure (see below) }\end{array}$ \\
\hline Environmental & $\begin{array}{l}\text { - Energy expenditure } \\
\text { Annual training plan and peaking } \\
\text { - Environmental factors such as cold, } \\
\text { heat and altitude } \\
\text { - Culture of sport } \\
\text { Travel } \\
\text { - Work/school } \\
\text { - Family/home } \\
\text { - Experience in sports }\end{array}$ & $\begin{array}{l}\text { Total daily energy expenditure, including resting metabolic rate, spontaneous physical activity, exercise } \\
\text { energy expenditure; evaluation of training/competition plan in discussion with coach; consideration of } \\
\text { environmental factors (eg, training at altitude); leanness/non-leanness sport; countries at risk for } \\
\text { inadequate food access and food safety concerns; work/school schedules and time for food preparation, } \\
\text { eating, recovery; level of athlete and experience }\end{array}$ \\
\hline
\end{tabular}

$A B C D E$, Anthropometric, Biochemical, Clinical, Dietary and Environmental; BMI, body mass index; DE, disordered eating; DXA, dual energy e-ray absorptiometry; EDs, eating disorders; FSH, follicle stimulating hormone; ISAK, International Society for the Advancement of Kinanthropometry; LH, luteinising hormone; MI, mass index; TSH, thyroid stimulating hormone.

athletes with DE rarely self-identify due to secrecy, shame, denial and fear of the possible consequences, ${ }^{11}$ specific questionnaire items designed to assess DE behaviours and attitudes have been incorporated into the medical history portion of the preparticipation physical examination (PPE) to facilitate the detection process. Optimum screening times occur at the PPE and annual health check-ups. Other opportunities occur when athletes are evaluated for related problems, such as amenorrhoea, stress fractures or recurrent injury or illness. ${ }^{11}$ The decision to implement a compulsory periodic health evaluation must be taken by the International Federations. ${ }^{59}$ However, as advised in the IOC position stand (2005) if suspicions of DE are raised from interpretation of questionnaire results, an in-depth personal interview by a member of the healthcare team should follow for a more accurate interpretation of circumstances. Until valid screening instruments are available we suggest that when healthcare providers suspect DE or EDs, an Anthropometric, Biochemical, Clinical, Dietary and Environmental (ABCDE) Assessment be used to evaluate athletes (table 4).

As suggested in the ACSM female athlete position stand and IOC position stand, athletes considered to be 'at risk' should meet with a sports nutritionist/dietitian and those who are not able to improve their eating habits/behaviour should be referred to a clinician for further assessment of EDs. ${ }^{11}{ }^{41}$ To assess energy availability, practitioners should assess training days (37 days) and include both prospective dietary records, possibly in conjunction with $24 \mathrm{~h}$ recalls and/or digital photography to increase validity. Exercise energy expenditure should be adjusted to energy expended at rest and daily activity, because energy availability is defined as the energy remaining after exercise energy expenditure has been subtracted from energy intake. This is especially critical when athletes train more than $1-2 \mathrm{~h} /$ day. Finally, if possible metabolic equivalent values should be confirmed by measures of oxygen consumption or other objective method. While daily activities vary among athletes depending on their level of competitiveness, assessments should include some measure of non-exercise adaptive thermogenesis (NEAT) or spontaneous physical activity (SPA) to evaluate the extent to which the resting component needs to be adjusted and to identify the extent to which athletes expend energy doing occupational tasks outside of organised exercise training. Unfortunately, assessing energy availability is difficult and may not be valid or reliable due to under-reporting of energy intake as well as over-reporting of exercise energy expenditure. 
The evaluation of body composition should be conducted by a trained member of the support staff. As shown in table 4 it is important to ask questions related to nutrition, body image issues inside and outside the sports arena and weight control, and psychological status as well as assessing overall well-being to diagnose a possible ED.

In line with the ACSM female athlete triad position stand and the IOC position stand, we recommend that when one triad disorder is present (such as amenorrhoea), the healthcare provider should screen for other triad disorders (such as LEA and low BMD). ${ }^{11}{ }^{41}$ We also agree on the recommendation regarding obtaining a DXA assessment in those female athletes with a cumulative total of 6 months or more of hypo-oestrogenism, $\mathrm{DE}$ or EDs, and/or a history of stress fractures or fractures from minimal trauma. The ACSM suggests re-evaluations recommended in 12 months in those with persistent triad disorders. For elite athletes we suggest re-evaluation after 6 months.

\section{When to raise the alarm?}

The last IOC position stand on the female triad states that if the ED specialist recommends treatment, the athlete should be considered 'injured' and must agree to treatment in order to continue training and competition', ${ }^{41}$ and 'For those affected athletes who agree to treatment, eligibility to continue training and competition while symptomatic would be determined on an individual basis by treatment staff.' At a minimum, the athlete would have to receive medical and psychological clearance, and would be required to follow a prescribed set of health maintenance criteria. These criteria would be determined on an individual basis, and would generally include, but not be limited to

- Complying with the treatment plan, and progressing towards therapeutic goals;

- Maintaining weight or achieving an appropriate level of body fat recommended by the treatment team;

- For female athletes, accepting/agreeing that resumption of menses or achieving menarche is needed for good health as well as a requirement for the continuation to participate in sport;

- Failing to meet the above criteria, the athlete would be withdrawn from training and competition;

- For those affected athletes who refuse treatment, training and competition would be withheld until they agree to participate in treatment. ${ }^{41}$

Thus, referring to the IOC position stand, ${ }^{41}$ in the case of extreme dieting and EDs the 'eligibility to continue training and competition while symptomatic would be determined on an individual basis by the treatment staff'. Our group also suggests declaring athletes with DE or ED as 'injured' and agree with the recommendation from the former position stand. Based on the existing recommendations for how to handle female athletes with one or more of the triad components and on requests from team physicians, coaches and elite athletes, the Norwegian Olympic Training Center (Health Department) developed, published and has now practiced for a year more concrete criteria than those listed in the existing IOC position stand. These criteria were developed for female and male athletes. Based on the positive feedback from team physicians, coaches and athletes we suggest being more concrete when it comes to maintaining weight or percentage of body fat recommended by the treatment team. A modified version of the recommendations for raising alarm and 'no start' criteria that have been developed and used at the Norwegian Olympic Training Center is presented in table $5 .{ }^{59}$ It is recommended that support staff in other countries also follow these guidelines, or to use them as a starting point for further developing this difficult field of sports medicine.

As can be seen in table 5, we suggest a body fat cut-off value of $5 \%$ for men and $12 \%$ for women. As stated previously, this guideline requires verification using more robust studies, and its use in the meantime must acknowledge the scope for individual differences. Also, instead of saying the athlete 'must agree that resumption of menses or achieving menarche', the Norwegian

Table 5 Criteria for raising alarm and 'no start' decisions

Alarm criteria
Women with a BMI below 18.5 and/
or body fat percentage below $12 \%$
and primary or secondary
amenorrhoea
Men with a BMI below 18.5 and/or
body fat percentage below $5 \%$ and
low testosterone

\section{Comments}

The BMI is widely used as a measure for 'relative body weight' and well known, but it should always be complemented by sitting height (s) measurement and determination of the Comic Index ( $\mathrm{C}=\mathrm{s} / \mathrm{h}$ ) by which the MI can be calculated, which considers individual leg length. In this case percentage of fat refers to DXA results. A problem not solved today is sufficient accuracy of field methods for fat determination. It has to be considered that accuracy of currently available field methods for total body fat determination is not sufficient and that also laboratory methods have limited accuracy ${ }^{1}$

Amenorrhoea $\geq 6$ months (>3 months for athletes younger than 18 years)

When amenorrhoea is related to restrain eating or low energy availability over time. Athletes using birth control pills, with regular cycles and values below $12 \%$ should also be considered 'alarm criteria'

Reduced BMD (either from last measurement or Z-score $\leq-1$ ) Athletes with physical complications based on the medical assessment

Uncooperative athletes or those showing a lack of progress in treatment

Athletes having a negative effect on other team members (dieting behaviour, bingeing and purging and instable mood)

Athletes unable to maintain a positive energy balance over time, no responsiveness to training, or showing fatigue and intolerance

No start criteria

Athletes of both sexes who meet the criteria for anorexia nervosa or severe other eating disorders such as bulimia nervosa with frequent vomiting and with electrolyte disturbances

Use BMD values from $\mathrm{L} 2-\mathrm{L} 4$ scans

Complications such as, electrolyte imbalance, fatigue, stress fracture should be assessed as a possible expression of low energy availability over time

Athletes with serious physical complications of weight loss/lack of energy availability, such as cardiac dysrhythmias, major oedema (swelling) in the body or fainting At least three of the criteria described above as 'alarm criteria'

A ban in this case is justified both by explicit consideration of the athlete's overall health, and of the more overarching goal of a sport founded on sound values and principles

Athletes who exhibit behaviours such as restrictive eating, maintenance of low weight, and excessive focus on matters pertaining to weight and food

$B M I$, body mass index; BMD, bone mineral density; DXA, dual energy e-ray absorptiometry; MI, mass index. 
recommendations suggest that adult and adolescent athletes with amenorrhoea for more than 6 and 3 months, respectively, are not allowed to compete if this symptom is combined with other symptoms of extreme dieting or EDs (table 5). As a result of their 'ED injury' the athlete's mental and physical health may be in serious jeopardy and continuing to compete may distract the athlete from devoting the attention needed for treatment. ${ }^{29}$ This is problematic and there is no evidence in terms of best practice regarding specific criteria for raising alarm or when to return to training and competition. The group, therefore, suggests applying the regulations from the Norwegian Olympic Committee until we have some evidence-based criteria. ${ }^{59}$ The examination, evaluation and decision regarding training and return to play must be based on picture total assessment of the athlete's health and the requirement in his/her sport. We also suggest that athletes who are not allowed to compete are evaluated after 4-6 weeks of suspension and new decisions are made based on the athlete's condition and behaviour.

\section{Tertiary prevention}

Treatment of an athlete with an ED should utilise a multidisciplinary intervention, which normally involves a physician, a gynaecologist, a sport nutritionist/dietitian, a physical therapist, an exercise scientist and in some cases, a psychiatrist or a psychologist. In addition, coaches and parents may be part of the treatment team if they have a positive relationship with the athlete. The younger the athlete, the more the involvement of the family is recommended. The primary goals of treatment should be to optimise energy availability, to control and manage the athlete's DE behaviour, to restore normal hormone levels and to monitor and treat other medical complications resulting from EDs. ${ }^{71}$ In terms of possible treatment initiatives for the athlete with DE behaviour and/or EDs, we refer to recent publications dealing with these issues. ${ }^{7} 2960$

\section{WILL IT HELP? \\ Education}

Developing and implementing education programmes that challenge the definition of optimum body composition and promote self-acceptance, healthy eating and reasonable training and recovery in athletes have been expected to be effective in prevention. ${ }^{61}{ }^{62}$ Randomised controlled trials (RCTs) aimed at preventing extreme dieting and the development of ED are lacking. However, a recent RCT that examined the effect of a 1-year school-based intervention programme on the development of new cases with ED, or symptoms associated with ED among adolescent elite athletes, was performed in Norway. ${ }^{19}$ First-year students $(n=465,93.8 \%)$ attending elite sport high schools $(n=16)$ were randomised at the school level to intervention or control groups. There were no new cases of ED among girls in the intervention schools, while $13 \%$ at the control schools $(p=0.001)$ at post-test 2 ( 1 year after the end of the intervention) had developed ED. The intervention showed a relative risk reduction of $90 \%$ for current dieting (OR 0.10, 0.02-0.54) and $53 \%$ reduction for repeated attempts at weight loss $(\geq 3$; OR $0.47,0.25-0.90)$. Interestingly, among boys, there was no difference in the risk of reporting symptoms between groups at post-test 1 or 2 . At post-test 2 there was only one new case of ED among the boys (belonged to a control school). Results from this study show that it is possible to prevent the development of new cases of ED and symptoms associated with ED in female elite athletes. ${ }^{19}$ However, more studies are needed, and intervention programmes need to be sport and gender specific. Furthermore, new education programmes/strategies should be evaluated routinely to determine their effectiveness with respect to changing knowledge, attitudes and behaviours.

\section{Modification of regulation}

The suggested modifications are based on the results from policies and procedures by governing bodies of US men's collegiate wrestling in the late 1990s that seem to have been effective in reducing unhealthy weight-loss behaviours and promoting competitive equity. ${ }^{63}$ Also, a call has gone out for the International Judo Federation (IFJ) to implement regulations to improve weight management behaviours among judo athletes, and for these regulations to be adapted by all national and regional federations. ${ }^{20}$ In contrast, the FIS employed a different strategy for preventing extreme dieting among ski jumpers. ${ }^{64}$ Instead of policing athlete behaviours, the FIS removed the motivation for ski jumpers to pursue extreme weight-loss objectives by penalising athletes when their BMI fell below a specific value. Finally, the suggested regulations are based on years of experience with elite athletes representing leanness sports. We have suggested that more objective judging should be implemented in the aesthetic sports. The removal of the overall impression score now adopted in figure skating is expected to de-emphasise the focus on leanness and that modification of some of the regulations in weight-class sports will reduce the number of athletes practicing extreme dieting and, therefore, the number of athletes at risk for developing EDs. However, problems persist despite new rules and regulations. New regulations should be carefully considered, and hypothetically tested and discussed among expert groups to evaluate their possible impact. The data from ski jumping shows that extreme approaches have probably been resolved but there are lingering issues.

\section{Raising alarm and 'no start' criteria}

To develop evidence-based criteria within this field is almost impossible and it is, therefore, the group's suggestion that the alarm and no start criteria developed and practiced by the Norwegian Olympic Training Center are applied in weightsensitive sports. ${ }^{59}$

\section{SUMMARY}

Participation in weight-sensitive sports may add risks for extreme dieting and EDs because athletes experience dual pressures of obtaining low weight and/or low percentage of body fat.

A low body mass and a low body fat content are considered to be important performance enhancement variables in many sports, and few question the weight-loss methods that are being followed. Extreme dieting, LEA and EDs may adversely affect health and performance, whereas extreme dieting constitutes a special health risk for the adolescent athlete. The result of extreme dieting and EDs is typically not an improvement in performance, as the athlete intends, but quite the opposite.

Thus, it is crucial to optimise nutrition knowledge and body composition by implementing healthy weight control as early as possible. Furthermore, it is suggested that those who have the main responsibility for the welfare of the athlete are educated appropriately; understanding how to approach and help affected athletes and to avoid unnecessary dieting. With regard to medical as well as performance considerations, it is important for support teams to know how to approach elite athletes who seek to change body composition and simultaneously prevent EDs. In addition, these support teams must know when to raise the alarm and how to advise athletes who are affected by extreme dieting or a clinical ED. Based on the present review 
we conclude that there is a need for (1) sport-specific and gender-specific preventive programmes, (2) established and recognised criteria for raising alarm and 'no start' decisions for athletes with EDs, (3) modifications of regulations in some sports and (4) the key areas for research to be identified. These research areas must include the development of standard methods for body composition assessment in elite athletes, screening measures for EDs among athletes, testing of prevention programmes, as well as investigating the short-term and long-term effects of extreme dieting and EDs on health and performance.

\section{New findings}

- Extreme dieting, low energy availability and eating disorders may adversely affect health and performance, and extreme dieting constitutes a special health risk for the adolescent athlete.

- Evidence-based criteria does not exist for start or return to play when it comes to extreme dieting and clinical eating disorders.

\section{How might it impact on clinical practice}

- With regard to medical as well as performance considerations, it is important for those who have responsibility for the welfare of the athlete to

- Optimise nutrition knowledge and body composition among the athletes by implementing healthy weight-control practice;

- Know how to approach elite athletes who seek to change body composition and simultaneously prevent eating disorders (EDs);

- Be educated in order to appropriately understanding how to approach and help athletes who are affected by extreme dieting or a clinical ED.

\section{Author affiliations}

${ }^{1}$ The Norwegian School of Sport Sciences, Oslo, Norway

${ }^{2}$ University of Colorado, United States Olympic Committee, Colorado, USA

${ }^{3}$ University of Arizona, Tucson, USA

${ }^{4}$ University of Western Australia, Perth, Australia

${ }^{5}$ School of Sport and Exercise Sciences, Loughborough University, Loughborough, UK

${ }^{6}$ Robert Gordon University, Aberdeen, UK

${ }^{7}$ Medical University of Graz, Institute of Biophysics, Graz, Austria

Contributors This article was designed and developed in cooperation with the members of the IOC Medical Commission Ad Hoc Working Group on Body Composition, Health and Performance: JS-B, NLM, TGL, TRA, RJM, ADS and WM.

Funding Meetings of the Ad Hoc Research Working Group on Body Composition, Health and Performance were financed by the International Olympic Committee.

\section{Competing interests None.}

Provenance and peer review Not commissioned; internally peer reviewed.

\section{REFERENCES}

1 Ackland TR, Lohman TG, Sundgot-Borgen J, et al. Current status of body composition assessment in sport: review and position statement on behalf of the ad hoc research working group on body composition health and performance, under the auspices of the I.O.C. Medical Commission. Sports Med 2012:42:227-49.
2 Sundgot-Borgen J, Garthe I. Elite athletes in aesthetic and Olympic weight-class sports and the challenge of body weight and body compositions. J Sports $\mathrm{SC}$ 2011:29(Suppl 1):S101-14.

3 Coelho GM, Soares EA, Ribeiro BG. Are female athletes at increased risk for disordered eating and its complications? Appetite 2010;55:379-87.

4 Currie A, Crosland J. Responding to eating disorders in sports-UK guidelines. Nutr Food Sci 2009;39:619-26

5 Meyer NL, Sundgot-Borgen J, Lohman TG, et al. Body composition for health and performance. A survey of body composition assessment practice carried out by the Ad Hoc Research Working Group on Body Composition Health and Performance, under the auspices of the IOC Medical Commission, accepted BJSM, Nov issue.

6 Loucks AB, Kiens B, Wright HH. Energy availability in athletes. J Sports Sci 2011:29 (Suppl 1):S7-15.

7 Sundgot-Borgen J, Torstveit MK. Aspects of disordered eating continuum in elite high-intensity sports. Scand J Med Sci Sports 2010;20(Suppl 2):112-21.

8 Torstveit MK, Sundgot-Borgen J. Are under- and overweight female elite athletes thin and fat? A controlled study. Med Sci Sports Exerc 2011;44:949-57.

9 Sundgot-Borgen J, Torstveit MK. Prevalence of eating disorders in elite athletes is higher than in the general population. Clin J Sport Med 2004;14:25-32.

10 Martinsen M, Sundgot-Borgen J. Higher prevalence of eating disorders among adolescent elite athletes than controls. Med Sci Sports Exerc 2013; 45:1188-97.

11 Nattiv A, Loucks AB, Manore MM, et al. American College of Sports Medicine position stand. The female athlete triad. Med Sci Sports Exerc 2007; 39:1867-82

12 De Souza MJ, Luciano AA, Arce JC, et al. Clinical tests explain blunted cortisol responsiveness but not mild hypercortisolism in amenorrheic runners. J App/ Physiol 1994;76:1302-9.

13 De Souza MJ, Arce JC, Pescatello LS, et al. Gonadal hormones and semen quality in male runners. A volume threshold effect of endurance training. Int I Sports Med 1994;15:383-91.

14 Dolan E, McGoldrick A, Davaneport C, et al. An altered hormonal profile and elevated rate of bone loss are associated with low bone mass in professional horse-racing jockeys. J Bone Miner Metab 2012;30:534-42.

15 Byrne S, McLean N. Elite athletes: effects of the pressure to be thin. J Sci Med Sport 2002;5:80-94.

16 Hannon J, Soohoo S, Reel J, et al. Gender stereotyping and the influence of race in sport among adolescents. Res Q Exerc Sport 2009;80:676-84.

17 De Bruin AP, Oudejans RRD, Bakker FC. Dieting and body image in aesthetic sports: a comparison of Dutch female gymnasts and non-aesthetic sport participations. Psychol Sports Exerc 2007:8:507-20.

18 Pietrowsky R, Straub K. Body dissatisfaction and restrained eating in male juvenile and adult athletes. Eat Weight Disord 2008;13:14-21.

19 Martinsen M, Bahr R, Holme IM, et al. Preventing eating disorders in sports: a cluster-randomized intervention study. Med Sci Sports Exerc, Publish Ahead of Print DOI: 10.1249/MSS.0b013e3182a702fc

20 Artioli GG, Gualano B, Franchini E, et al. Prevalence, magnitude, and methods of rapid weight loss among judo competitors. Med Sci Sports Exerc 2010;42:436-42.

21 Rosendahl J, Bormann B, Aschenbrenner $\mathrm{K}$, et al. Dieting and disordered eating in German high school athletes and non-athletes. Scand J Med Sci Sports 2009;19:731-9

22 Byrne S, McLean N. Eating disorders in athletes: a review of the literature. I Sci Med Sport 2001;4:145-59.

23 Beals KA, Hill AK. The prevalence of disordered eating, menstrual dysfunction, and low bone mineral density among US collegiate athletes. Int I Sport Nutr Exerc Metab 2006:16:1-23.

24 Rauh MJ, Nichols JF, Barrack MT. Relationships among injury and disordered eating, menstrual dysfunction, and low bone mineral density in high school athletes: a prospective study. J Athl Train 2010;45:243-52

25 Torstveit MK, Sundgot-Borgen J. Participation in leanness sports but not training volume is associated with menstrual dysfunction: a national survey of 1276 elite athletes and controls. Br J Sports Med 2005;39:141-7.

26 Hagmar M, Berglund B, Brismar K, et al. Body composition and endocrine profile of male Olympic athletes striving for leanness. Clin J Sport Med 2013;23:197-201.

27 Hetland ML, Haarbo J, Christiansen C. Low bone mass and high bone turnover in male long distance runners. J Clin Endocrinol Metab 1993;77:770-5.

28 Smathers AM, Bemben MG, Bemben DA. Bone density comparisons in male competitive road cyclists and untrained controls. Med Sci Sports Exerc 2009:41:290-6

29 Thompson RA, Sherman RT. Eating disorders in sport. New York: Routledge, 2010.

30 Beals KA. Disordered eating among athletes: a comprehensive guide for health professionals. Champaign, IL: Kuman Kinetics, 2004.

31 Ireland ML, Nattiv A. The female athlete. Philadelphia: WB Saunders, 2002

32 Sundgot-Borgen J, Danielsen K, Klungland-Torstveit M. Female former elite athletes suffering from eating disorders during their career. A 15-20 year follow-up. Med Sci Sports Exerc 2012:44:267-958.

33 Holderness CC, Brooks-Gunn J, Warren MP. Co-morbidity of eating disorders and substance abuse review of the literature. Int J Eat Disord 1994;16:1-34. 
34 Beals KA, Meyer NL. Female athlete triad update. Clin Sports Med 2007;26:69-89.

35 Soric M, Misigoj-Durakovic M, Pedisic Z. Dietary intake and body composition of prepubescent female aesthetic athletes. Int I Sport Nutr Exerc Metab 2008; $18: 343-54$

36 Weimann E, Witzel C, Schwidergall S, et al. Peripubertal perturbations in elite gymnasts caused by sport specific training regimes and inadequate nutritional intake. Int I Sports Med 2000;21:210-15.

37 Caine $\mathrm{D}$, Lewis $\mathrm{R}, \mathrm{O}^{\prime}$ Connor $\mathrm{P}$, et al. Does gymnastics training inhibit growth of females? Clin I Sport Med 2001:11:260-70.

38 Roemmich JN, Sinning WE. Weight loss and wrestling training: effects on nutrition, growth, maturation, body composition, and strength. J App/ Physiol 1997;82:1751-9.

39 Ingjer $F$, Sundgot-Borgen J. Influence of body weight reduction on maximal oxygen uptake in female elite athletes. Scand J Med Sci Sports 1991;1:141-6.

40 American Academy of Pediatrics Committee on Sports Medicine and Fitness. Promotion of healthy weight control practices in young athletes. Pediatrics 2005;116:1557-64.

41 Sangenis P, Drinkwater B, Loucks A, et al. International Olympic Committee Medical Commission Working Group Women in Sport: position stand on the female athlete triad. International Olympic Committee. 2005. http://www.olympic.org/Documents/ Reports/EN/en_report_917.pdf

42 Troy K, Hoch AZ, Stavrakos JE. Awareness and comfort in treating the female athlete triad: are we failing our athletes? WMJ 2006;105:21-4.

43 Mettle S, Mitchell N, Tipton KD. Increased protein intake reduces lean body mass loss during weight loss in athletes. Med Sci Sports Exerc 2010;42:326-37.

44 Garthe I, Raastad T, Sundgot-Borgen J. Long-term effect of weight loss on body composition and performance in elite athletes. Int I Sport Nutr Exerc Metab 2011:21:426-35.

45 Friedl KE, Moore RJ, Martinez-Lopez LE, et al. Lower limit of body fat in healthy active med. J Appl Physiol 1994;77:933-40.

46 Müller W, Horn M, Fürhapter-Rieger A, et al. Subcutaneous adipose tissue measurement I: ultrasound imaging technique compared to skinfold measurement. Br J Sports Med 2013:47:1028-35.

47 Müller W, Horn M, Fürhapter-Rieger A, et al. Subcutaneous adipose tissue measurement II: inter-observer reliability of ultrasound technique. Br I Sports Med 2013;47:1036-43.

48 Cantu RC, Micheli LJ. eds American College of Sports Medicine: quidelines for the team physician. Philidelphia, USA: Lea \& Febiger, 1991.

49 Slater GJ, Rice AJ, Sharpe K, et al. Impact of acute weight loss and/or thermal stress on rowing ergometer performance. Med Sci Sports Exerc 2005;37:1387-94.
50 Muller W. Determinants of ski-jump performance and implications for health, safety and fairness. Sports Med 2009;39:85-106.

51 Muller W. Towards research-based approaches for solving body composition problems in sports: ski jumping as a heuristic example. Br I Sports Med 2009:43:1013-19.

52 Muller W, Groschl W, Muller R, et al. Underweight in ski jumping: the solution of the problem. Int I Sports Med 2006;27:926-34

53 Garner DM. Eating Disorders Inventory-2: professional manual. Odessa, FL: Psychological Assessment Resources Inc, 1991.

54 Garner DM, Olmsted MP, Bohr Y, et al. The Eating Attitudes Test, psychometric features and clinical correlates. Psychol Med 1982;12:871-8.

55 Fairburn CG, Cooper Z, O'Connor ME. Eating Disorder Examination (Edition 16.0D). In: Fairburn CG. ed Cognitive behavior therapy and eating disorders. New York: The Guilford Press, 2008:265-308.

56 Torstveit MK, Rosenvinge JH, Sundgot-Borgen J. Prevalence of eating disorders and the predictive power of risk models in female elite athletes: a controlled study. Scand J Med Sci Sports 2008;18:108-18.

57 Hagmar M, Berglund B, Brismar K, et al. Hyperandrogenism may explain reproductive dysfunction in Olympic athletes. Med Sci Sports Exerc 2009;6: 1241-8.

58 Basiotis PP, Welsh SO, Cronin FJ, et al. Number of days of food intake records required to estimate individual and group nutrient intakes with defined confidence. J Nutr 1987:117:1638-41.

59 Skårderud F, Fladvad T, Garthe I, et al. The malnourished athlete - guidelines for intervention. Tidsskr Nor Laegeforen 2012;132:1944. http://tidsskriftet.no/article/ 2866547/en_GB

60 Bonci $C M$, Bonci $L$, Granger $L R$, et al. National athletic trainers' association position statement: preventing, detecting, and managing disordered eating in athletes. J Athl Train 2008:43:80-108.

61 Bratland-Sanda S, Sundgot-Borgen J. Eating disorders in athletes: overview of prevalence, risk factors and recommendations for prevention and treatment. Eur $J$ Sport Sci 2013;13:499-508.

62 Ljungqvist A, Jenoure P, Engebretsen L, et al. The International Olympic Committee (IOC) Consensus Statement on periodic health evaluation of elite athletes March 2009. Br J Sports Med 2009;43:631-43.

63 Oppliger RA, Utter AC, Scott JR, et al. NCAA rule change improves weight loss among national championship wrestlers. Med Sci Sports Exerc 2006;38: 963-70.

64 FIS . International Ski Federation World Congress. Miami, FL, USA, 2004. 